\title{
Empowering Students to Teach Flight Dynamics and Flight Simulation En- hanced Learning through Applied Modeling
}

Mr. Muhammad Omar Memon, University of Dayton

Muhammad Omar Memon is a doctorate student and a part time instructor for Flight Vehicle Performance at the University of Dayton.

\section{Dathan Erdahl Ph.D., University of Dayton Research Institute}

Dathan Erdahl is a research engineer with the University of Dayton Research Institute and has been an adjunct faculty member with the School of Engineering since 2008. He received his M.S. (2000) and Ph.D. (2005) degrees from the Georgia Institute of Technology and has been working in the areas of nondestructive evaluation, system automation, robotics and controls. His current research interests are embedding NDE into integrated robotic systems for inspection, performance monitoring, feedback and control.

\section{Mr. Saad Riffat Qureshi, University of Dayton}

Graduate Student at University of Dayton Lecturer, Institute of Space Technology, Pakistan Masters in Engineering in Aeronautical Engineering, University of Glasgow, U.K. (2011) 
Empowering Students to Teach Flight Dynamics and Flight Simulation Enhanced Learning through Applied Modeling 


\begin{abstract}
Students saturated with theoretical classes are prone to disengagement from the instructor and course material. To increase student engagement and provide an enriched learning environment that combines practical experiences with theoretical knowledge, an alternative approach to a flipped classroom was explored. With a senior and graduate mix of 28 students, roles in the Flight Vehicle Performance (FVP) course were partially flipped, as students were asked to take ownership of their learning through two main efforts. First, integration of the Merlin Flight Simulator early in the course built off of previous use to provide a practical exposure to the course material, even before it was presented in class. Second, the students were required to prepare lectures that cumulatively covered around $25 \%$ of the core course material. These methods greatly enlarged the learning platform of the class. Assessment of the lecture assignments was uniquely based on active participation by the students, including the learning process, delivery of the assigned content, and students' ability to keep the audience engaged. Class performance through projects and homework assignments revealed that students enhanced their knowledge of aircraft stability and control through flight simulator experience, iterative homework assignments, and by preparing and presenting assigned lectures. Reflections from the students showed that they greatly benefitted from the intuitive theoretical learning through the use of flight simulator.
\end{abstract}

\title{
Introduction
}

In the field of engineering, development of both critical and creative thinking in college students is essential. Very little research has been done on the development of creative thinking towards finding out-of-the-box solutions to engineering problems. Provansik et al. related the encouragement of creativity in classrooms to the strength of American education system (Provasnik, et al., 2012). Innovative teaching techniques that strategically enhance creative thinking of engineering students and focuses on their ability to solve problems is increasing in American colleges (Daly, Mosyjowski, \& Seifert, 2014; Brent \& Felder, 2014). According to researchers, the development of creative thinking can sometimes be a more abstract and overwhelming task for the educators (Diaz, 1992; Brandsford, 1983). It is very important for an educator to make the students fully understand the problem before they have the chance to think of creative solutions while keeping in mind the importance of real-world application. By having the students understand the theory by means of application, the development of creative thinking takes place, transforming the students into better problem solvers (O'Brien and Abulencia, 2010).

In a conventional classroom, lower levels of Bloom's taxonomy: knowledge, comprehension, and application are practiced (Bloom et al., 1956). The instructor introduces a topic, shows its applications, and assigns practice problems to the students with the goal of repetitive solutions making them familiar with engineering concepts. Reverse engineering or learning through practice is a fairly new practice implemented by engineering instructors. In this method of instruction, the focus is geared towards the upper levels of Bloom's taxonomy: design, explanation, and analysis (Bloom et al., 1956). While this method is not unheard of for a fundamental engineering course, it is uncommon for an advanced (senior/graduate) level course. The Flight Vehicle Performance (FVP) offering covered in this paper is an aggressive four credit hour course. Students are taught to solve the full equations of motion for an aircraft, focusing on the differences between steady-state flight and small-perturbation solutions. A model of the 
aircraft is built-up from introducing stability and control derivatives that allow linearization of solutions near specific operating conditions. As part of aircraft performance analysis, the students consider various operations in the flight envelope to characterize the behavior of an aircraft model they created to mimic an existing aircraft. All of these topics are pulled together to create a simulation of the vehicle in the final project, based on original code.

Learning through practice was implemented in the FVP course by two methods; integration of Merlin Flight Simulator early in the course and partially flipping instructor roles in the classroom. Figure 1 shows the flow of the FVP course starting with the hands-on experience to the Flight Simulator followed by the theoretical knowledge given in the class (both instructor and student-taught lectures) and combining the two to execute the modeling and simulation phase of the project.

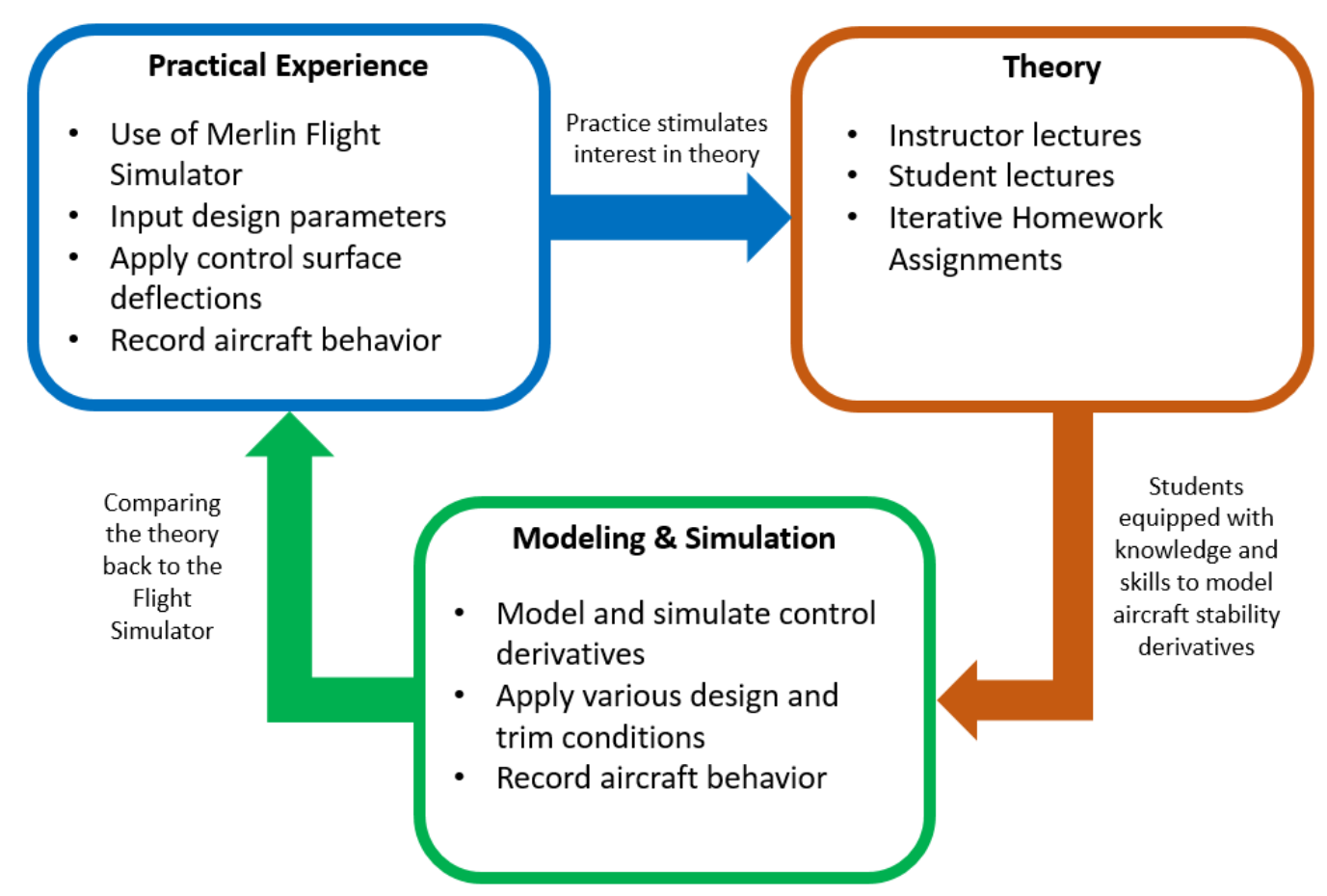

Figure 1. Flow of syllabus for the FVP class starting off with hands-on experience in the Flight Simulator while the theory is taught in class followed by student's initiative to the modeling and simulation of aircraft performance parameters.

\section{Classroom Demographics and Breakdown}

Course demographics play a part in the type of assignments, as language barriers, cultural norms and a diversity of previous coursework change the relevance of the approaches being considered (Brent and Felder, 2014). For the class that is being covered by this paper, the 
classroom size and makeup were typical for the university. The class is cross-listed as a 400 and 500-level, four credit hour course. A total of 28 students were on the roster, and only five of them were graduate students. Four out of the five graduate students were working full-time as engineers in closely-related fields. This meant that they had a better perspective on how the course content would be valuable to them in performing their job. In addition, they were also only taking one or two courses at a time, leaving more opportunity for them to explore alternative learning approaches and participate in extra-curricular activity. Of the remaining 23 students, at least 15 of them were taking the course as a requirement for their degree during their final semester at the university. They were also working to complete their capstone design projects, and many of them were traveling for interviews. However, the advantage of catching them at this position in the departmental study plan is that the students were also more aware of the potential benefit of the course on their career, and the concept of adding this course project to their resume was very attractive. In spite of catching the students at the end of their college experience, the classroom demographics were favorable.

When making decisions on the applicability of any set of techniques or approaches to teaching a course, several factors must be balanced. The position of the course within the departmental curriculum could affect the course load and the ability of the students to adapt to new teaching methods. Typical course size will determine whether a particular technique will be successful, especially if there is a need for individualized attention from the instructors or individual effort from the students. From the beginning, student groups needed to be established, but in prior experience random assignment of groups had led to inconsistency of performance. Instead, a brief survey was conducted to capture a snapshot of their prior experience, strongest skill sets and weakest skills of relevance to the course. Based on the initial survey, the instructors created the groups (three to four members) to balance the skills and experience. For instance, students with prior experience using the flight simulator were paired with students who were more skilled in computer programming. Creating the groups by matching skills not only helped to equalize the talent in the groups, but it also separated students from some of their friends. In order to meet department guidelines for graduate students, the graduate students were kept in groups separate from the undergraduate students, because evaluation criteria were more rigorous for these students. For each one of the assessment techniques, all students were evaluated on their individual performance as well as group work through different evaluation documents. Individual performance was assessed through peer evaluations in combination with assessments by the instructor, based on personal interaction with the groups.

\section{Use of a Flight Simulator}

A wide range of design and performance parameters define the stability and control of an air vehicle and little variations have the potential to dramatically change the performance of the flight. While the use of a full flight simulator is not common for Flight Dynamics classes, a recent study has shown evidence of students' enhanced learning through the use of a flight simulator (Dannenhoffer and Green, 2017). The authors showed the use of a full-motion flight 
simulator, based on X-Plane simulation software, as a basic lab experience for the Aircraft Performance and Dynamics course at Syracuse University. The authors showed that students got first-hand knowledge and appreciation of the importance of aircraft stability, while no direct measures of improvements were shown. In the present paper, Merlin Flight Simulator was specifically used as an essential tool for students to understand flight stability and control through practice while relating it to theory. This enhanced students' understanding of the theoretical flight dynamics as they could explore the effects of varying geometric parameters on the aircraft. The physics based Merlin Flight Simulator provides a realistic simulation, using the build-up approach to simulate the flight dynamics of any designed aircraft. Figure 2 shows the Merlin Flight Simulator at the University of Dayton. The flight simulator features three modeling versions; Excalibur I, II, and III. The Excalibur software is a fully nonlinear, transonic, real-time application that operates within six degrees of freedom. This software requires geometric design data, rather than computational code, in order to model and simulate the aircraft. Beyond the basic Excalibur I, Excalibur II features more detailed methods to model the wing and fuselage, while giving the user more design freedom over control mapping. As a step further, Excalibur III introduces aero-elasticity effects into the modeling. Since the Merlin Flight Simulator was integrated for the first time in the FVP course and the students were fairly new to the experience, Excalibur I software was sufficient for this course. Along with the Excalibur software manual, students were given instructions by the professor on the use of Flight Simulator. When working in the simulator facility, laboratory assistants were on hand to answer questions and facilitate efficient and safe interaction with the system hardware.

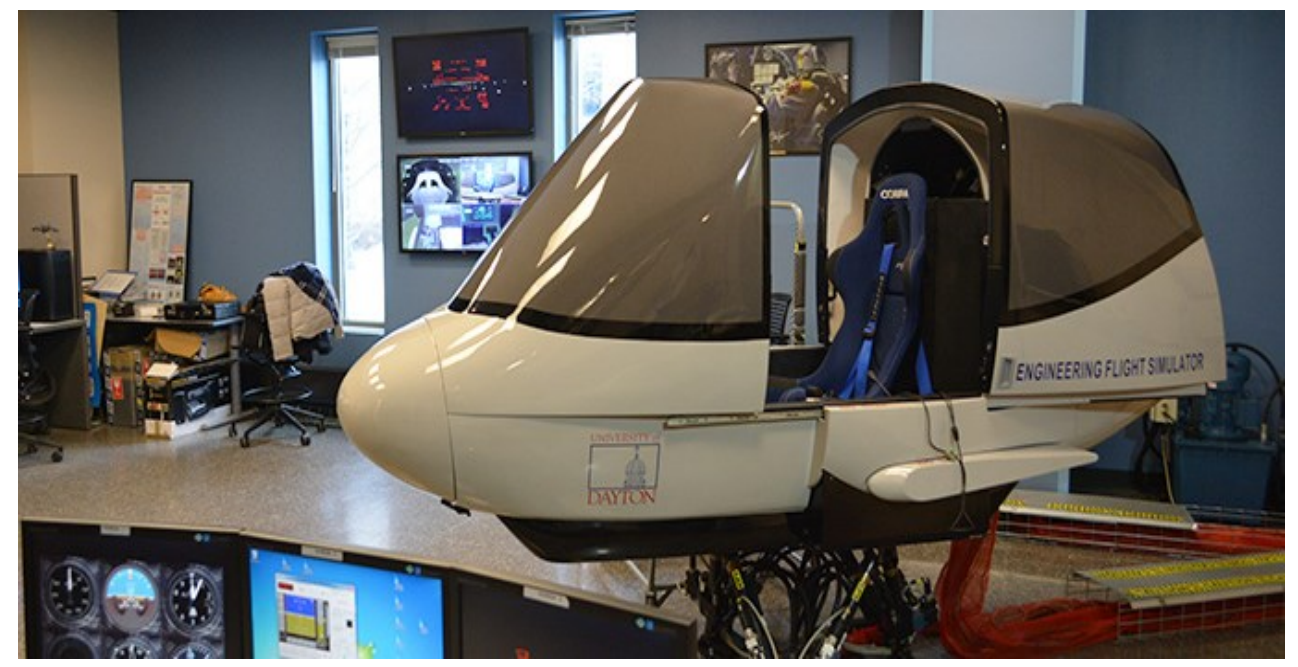

Figure 2. Merlin Flight Simulator at the University of Dayton

\section{Integrating Merlin Flight Simulator}

With student groups (of three to four) already created for the final project, the project was divided into two parts; understanding aircraft stability and control through use of the Merlin 
Flight Simulator and modeling and simulation of the stability derivatives using a computer program. In-class lectures were strategically placed in the timespan between the two parts of the project. Early in the semester, student groups went into the simulator with very basic knowledge of the software and their chosen airplane design. Design parameters from a wide selection of aircraft were obtained from the Aircraft Dynamics textbook. These range from Class I-IV aircraft. Students were also allowed to develop their own design based on prior knowledge of aircraft design. Groups were tasked to obtain various stability and control derivatives based on published parameters. A number of pitch, roll, and yaw maneuvers were required in addition to take-off and landing. These tasks enabled students to change several maneuverability parameters to understand their effects and show evidence of how the aircraft behaved. A student stated "Stability and Control is visually displayed in the Merlin Flight Simulator and therefore it is crucial for all students to sit in the simulator and experience the effects of changing parameters on aircraft." As students practiced their chosen aircraft in the Flight Simulator, class lectures on stability and control unfolded in a sequential manner providing the students a theoretical insight into what they had experienced. According to a student, "The Merlin Flight Simulator extremely aided my understanding of aircraft stability and control. When first inputting our aircraft, it was extremely unstable. We had to figure out why and how to fix it. With the flight simulator, we could make changes and see how they affected the aircraft. Without the simulator, we would have to rely simply on equations, which are much harder to interpret than from practical experience."

\section{Flipping Instructor Roles}

Another method to draw students into course content is to force them to engage through a reversal of roles. Conventionally, instructors present technical content to the class and the students serve as a rather quiet audience. By requiring student groups to take ownership of a portion of the course content, they had to start paying attention to the content and work to assimilate the course material into a framework that they could use to explain the sections they were responsible for teaching. The biggest motivation for implementing the "reversal of roles" technique was, in doing so, students were encouraged to ask the question "why" rather than "how," which would allow them to be more engaged in the course content. Material was assigned at the beginning of the course to the students so the impact of drawing them into the course content would pay dividends throughout the remainder of the course.

\section{Lecture Assignments}

Several avenues were pursued to increase student engagement in the FVP course. Although shaking up their learning opportunities with more radical processes, such as interfacing with the flight simulator, was a significant deviation from traditional classroom procedure, a certain amount of new material still needed to be introduced to formalize the information and provide a basis for the modeling and simulation part which were to be later introduced in the course. The topics covered by these more traditional lectures formed the basis of modeling 
assumptions, mathematics, and the physical understanding of the effects that variations in the environment or the aircraft structure have on performance and aircraft control. Observations made by the instructors of the students during early lectures showed a disengagement typical of a lecture format, and attempts to verbally draw them into the subject through active learning methods were not successful. Either the class was just large enough that the students were intimidated from speaking up, or the students weren't being drawn into the material. Since the university is a relatively small program, the students are probably fairly familiar with each other, so being shy in front of their peers was probably not the main influence keeping them from participation.

\section{Preparation Process}

Empowering the students in the classroom was a challenge, particularly with complex technical content. Generally, giving away the ownership could jeopardize the quality of the delivery and promote lack of attention from the audience. However, much attention was paid to the process of equipping students to prepare and present their assigned content. Two chapters that defined the longitudinal and lateral stability of the aircraft were selected from Aircraft Dynamics textbook used in the course (Napolitano, 2012). Even though these chapters consisted of some of the most complex course content, students had some practical understanding of the longitudinal and lateral stability in the flight simulator. Two chapters were selected for coverage by the student groups. These two chapters were primarily review of material that either overlapped or was closely related to previously completed courses. The structure of the chapters had multiple sections that led to a final section that wrapped the details together with more challenging math models. The last portion of each of the two chapters was assigned to the graduate student groups. Each student in the group was required to present some portion of the assigned topic. The total amount of material aimed to have been covered in the course was not sacrificed due to the student lectures. This is due to that fact that each student group was given 30 to 40 minutes to present (10 minutes per student), concluding all student lectures in five classes. This approach worked well for the 28-student class size. For larger classrooms, alternative approaches for individual student participation and evaluation may be necessary.

While giving the control and freedom to the students to prepare lecture notes, PowerPoint slides, handouts etc., instructors ensured the quality of the content by meeting individual students as needed. Prior to the meeting, the students were to research their topic, prepare some slides or material to present and come ready for a fast-speed dry run. The instructors came to the meetings with specific goals: verify that the group is ready to present, ensure that the students are covering all of the required information, and evaluate the balance of the workload between the members of the group. Figure 3 shows the flowchart of the lecture assignment preparation that went into the final presentation by the students. Students were assessed based on their ability to cover the given material, present lecture that is effective and understandable for the class, and answer questions. Extra points were given to the groups that provided handouts and/or lecture summary to the class before or after their assigned lecture. 


\section{Lecture Assignment Preparation Process}

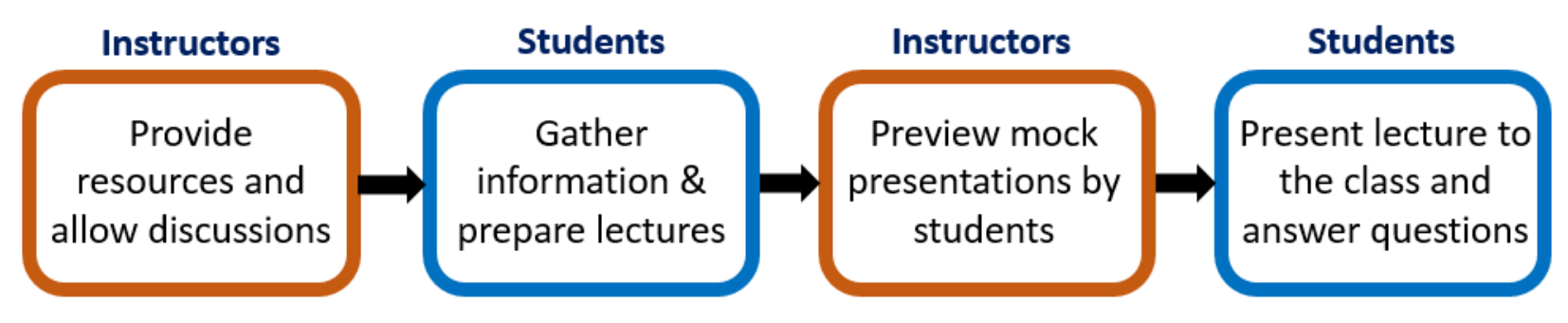

Figure 3. Flowchart of the lecture assignment preparation process showing students and instructors roles for different parts of the process.

Although delivering the lecture was not comfortable for all of the students, the act of requiring participation in the teaching process provided benefits for the remainder of the course. Prior to the assignment, the students were completely passive, and the instructors had a difficult time gaging student understanding. Treating them like valued peers paid dividends because it lowered the barriers between the class and the instructors. Students asked questions during the lectures, approached the instructors after class with additional questions and feedback on the lectures, and actively participated in ensuring the quality of material in the class. Because of their engagement, the tone of the course became more collegial and less structured.

\section{Iterative Homework Assignments}

Handing assignments to students has been a long-standing tradition within schools, colleges and universities with the focal point being practicing the taught course content outside of the classroom. Assignments also serve the purpose of assessing students' understanding of the course material while serving as a constant feedback on class performance for the instructor. However, in most cases, homework assignments end up assessing students' ability to solve problems rather than learning through practice. The opportunity of learning through the mistakes is somewhat lost when students are provided with correct solutions to the homework along with the grades.

Following the learning strategies presented in this paper, students in the FVP class were given the opportunity to iterate and improve on their homework assignments multiple times to learn from their mistakes. To achieve this, students were assigned homework with an initial deadline for submission with a caveat that they could resubmit it (within one week of provided feedback) if they could not get it correct the first time. Feedback on the mistakes was provided by the teaching assistant (TA) along with hints to where students might have gone wrong. This allowed students to take a fresh look at their solution for the assignment. According to a student, "in most cases I usually receive graded homework and throw it in a folder. I never return to it unless I am studying for a test. I think giving us the option to correct homework was very 
beneficial because it encouraged me to tackle the gaps in my understanding while the course material was still fresh in my mind." There were only four homework assignments for this course which comprised of $20 \%$ of the total course grade. The overall course breakdown is summarized in Table 1. Each homework assignment served as a self-contained mini-project, which consisted of theoretical derivations, numerical modeling, and detailed simulation in some cases. Allowing students to re-submit an incorrect assignment forced them to reanalyze their approach to the problem, judge and correct their mistakes and, hopefully, build skills that will leave them well-prepared for solving real-world problems.

Table 1 Course Breakdown showing percentage for each assessment

\begin{tabular}{|l|c|}
\hline Assessment & Weight (\%) \\
\hline Homework Assignments & $20 \%$ \\
\hline Lecture Assignment & $15 \%$ \\
\hline Midterm Exam & $15 \%$ \\
\hline Final Project Part 1 (Flight Simulator) & $20 \%$ \\
\hline Final Project Part 2 (Modeling \& Simulation) & $30 \%$ \\
\hline
\end{tabular}

The iterative assignment technique was very beneficial for the students to say the least. According to one student, "the iterative homework assignments were a cornerstone of my learning in flight vehicle performance". A significant improvement in the class average was observed as the class progressed through the semester. For each of the homework assignments, there was always a few people who were resubmitting which not only improved their individual scores but also impacted the class average. Figure 4 shows the class average comparison of the first and second attempt to each of the four homework assignments in the FVP course. The class average during the first two homework assignments was less than $70 \%$ due to the lack of understanding of the course material and being unaware of the class expectations. The opportunity of resubmission of the homework assignment was much appreciated by the students who scored $81 \%$ on an average for the first two homework assignments. The class average for homework 3 and 4 was relatively better in the first attempt which further increased on the second attempt. While the resubmission for each of the homework assignments was optional, a significant number of students reattempted the first two assignments, as shown in Figure 5. Figure 5 also indicates that closer to the end of the semester, the number of resubmissions decreased (from $64 \%$ to $18 \%$ ) either because most students scored well the first time, or they were caught up with project and other requirements of the class. 


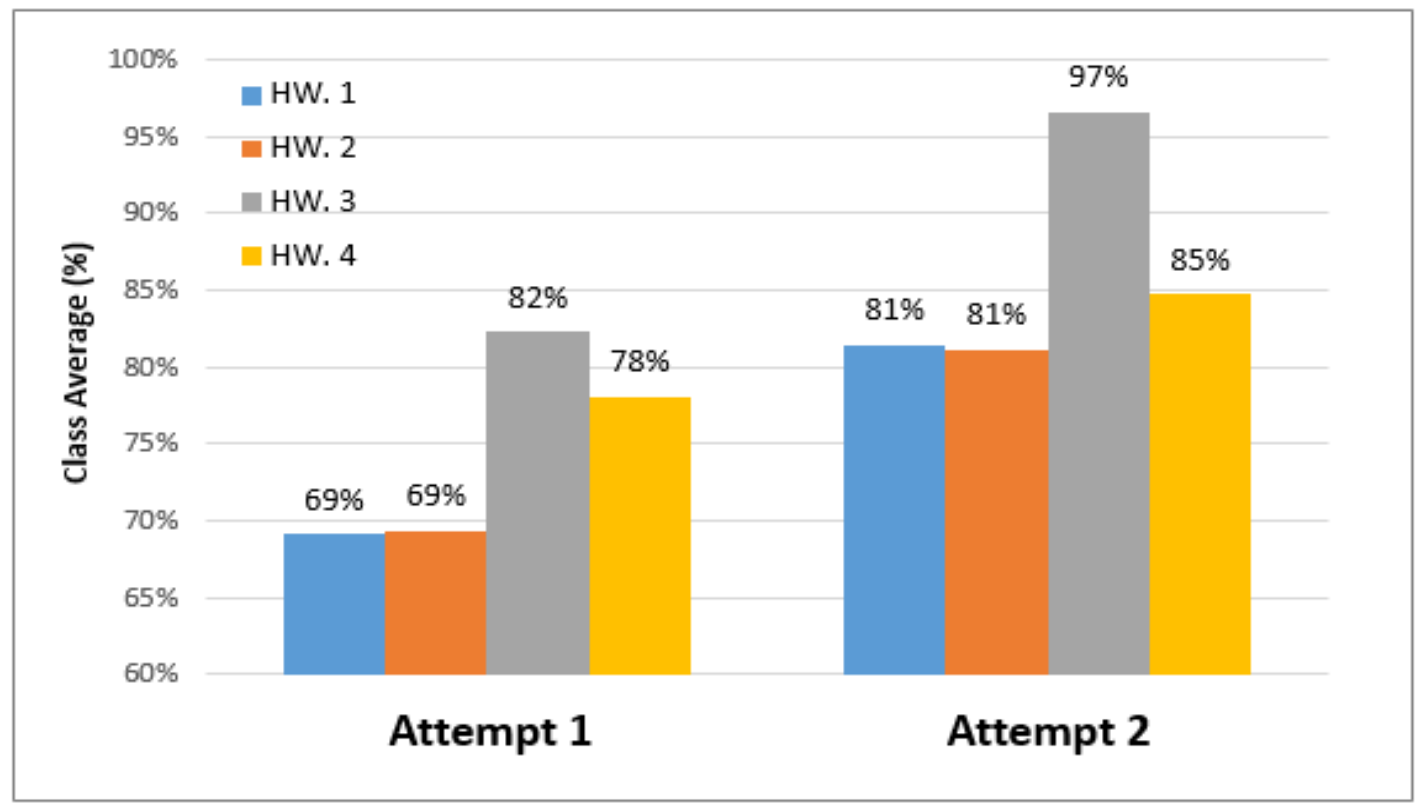

Figure 4. Comparison of the average percentage of the class for first and second homework submission attempt, showing substantial increase in the class average in the second attempt.

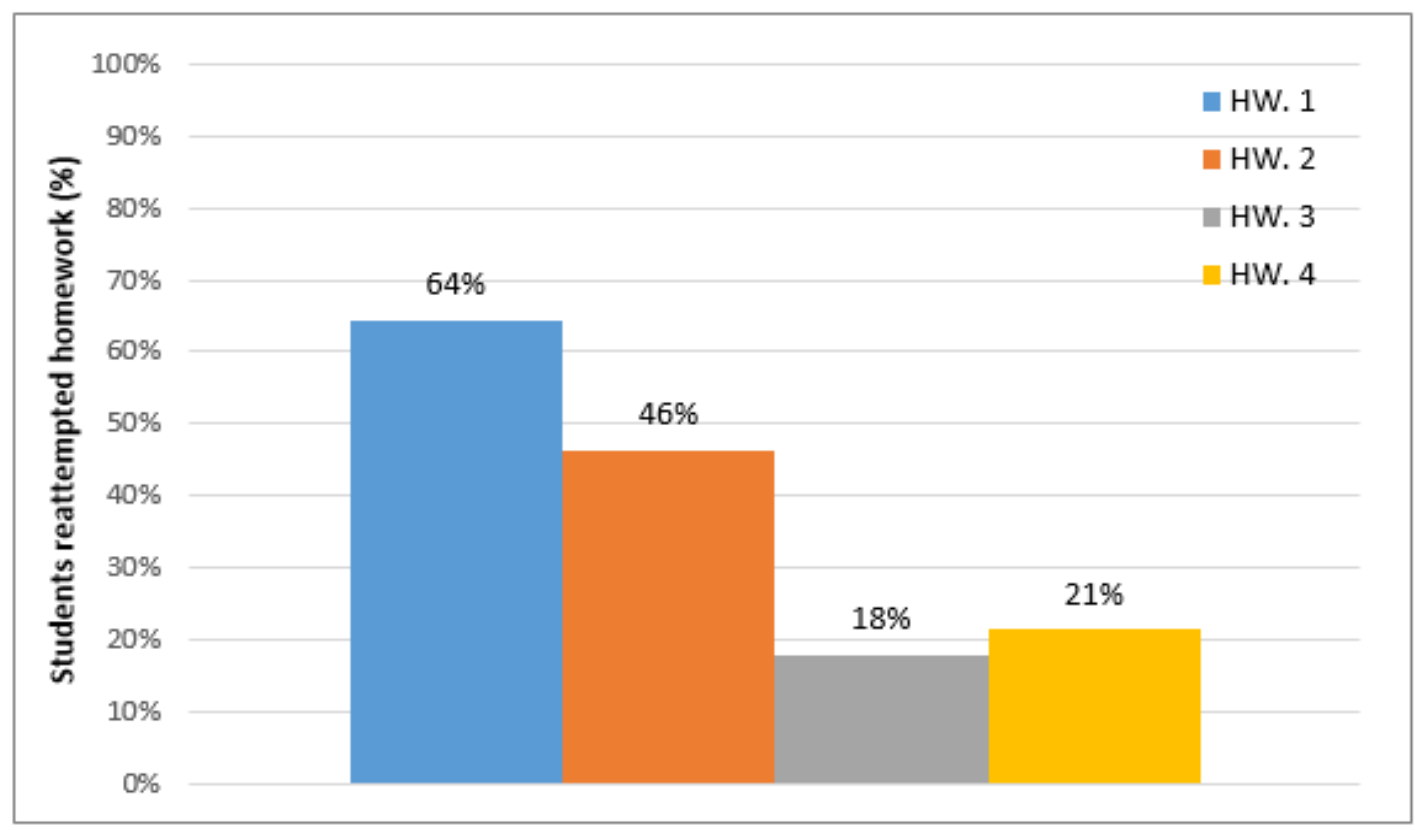

Figure 5. Percentage of students re-attempted each homework assignment showing gradual decrease as the course ended indicating stronger grasp of the course material. 


\section{Results/Discussion}

The main objective of the FVP course was to instill in students the aircraft dynamics concepts, mathematical models, and their relevance in aircraft longitudinal and lateral stability. To achieve this objective, various aforementioned novel techniques were used. Distilling to the theoretical knowledge of the flight stability and control from experience gained in the flight simulator turned out to be a tremendous initiative for the class. Students realized the importance of this initiative as they begun working on the modeling and simulation of the stability derivatives. According to a student, "I was able to learn this way with flight experience first then equations after, and I fully believe this allowed me to excel." Working with the flight simulator and coming up with the parameters to input into it helped the student to visualize how different parameters affect the behavior of the aircraft. After inputting the calculated parameters into the simulator, the student had to find and correct stability issues related to their design aircraft through iteration. Another student stated, "Personally, the Flight Simulator was my favorite part of the class. After finding the necessary aircraft information, using the Merlin Flight Simulator gave myself and the group first-hand experience of how changing different parameters affected the overall performance of the aircraft."

Lecture assignments forced the students to get deeper understanding of each parameter and how those all come together for a stable flight. One of the students stated "the group lecture assignments I think were a necessity for this class. I learned a lot in my group lecture assignment and I was able to go deeper into learning the material on my own and it made me more acclimated to the material". Feedback from the students, especially seniors who were ready to graduate, showed that lecture assignments also provided them with a professional development activity by improving on their communication and presentation skills. In addition, the instructors noted increased classroom participation following the lecture assignment. Once the students participated in teaching, they were less afraid to ask questions, request clarifications, and bring additional insight into classroom activities. "Throughout the class some of the methods such as the iterative homework the class lectures were very helpful in learning the material. The iterative homework assignments were conducive to learning what we did wrong and why it was wrong", a student stated. Iterative homework assignments improved the students' comprehension of the course. The class average increased significantly during the latter part of the course. The percentage of students resubmitting the homework to acquire better grades also reduced towards the end of the course, hence, providing some proof that the flight simulator and lecture assignments had enhanced the understanding of the course content for the students.

After learning experientially in the simulator and theoretically through lectures and homework, the students were able to effectively apply this knowledge to create their own simulation. Completion of a mathematical model in a small group was the ultimate proof of their understanding. In order to validate their model, they needed to apply their physical understanding of the stability and control derivatives, and they had to identify the effects of each parameter at different flight conditions. Students were able to compare the control deflections 
obtained from the flight simulator data to those modeled using a computer program, which helped them gain confidence in their own knowledge and engineering judgment. Tying the theory back to the practice is a unique way of learning complex course content such as one in the FVP course. According to a student, "I would say that working with the Merlin Flight Simulator to find and fix stability issues and documenting and describing each parameter to compare with the simulation was the most beneficial part of this project”. While in such learning techniques (as introduced in the FVP course), it may be difficult to pinpoint what exactly contributed to individual student learning, student feedback showed that each one of them uniquely enhanced their understanding of the subject.

\section{Conclusions}

Students in the Flight Vehicle Performance course at the University of Dayton were beneficiaries of an enriched learning environment that was created through an alternative approach to flipping the classroom. Required to take partial ownership of their learning through the use of a Merlin Flight Simulator early in the course, students experienced the core course content with prior practical knowledge. Additionally, flipping instructor roles in the classroom for $25 \%$ of the core course content initiated the students into taking professional approach to learning and applying new material. Lowering the barrier between the instructor and the student created a more interactive learning environment, and it helped the students to internalize theoretical concepts. Iterative homework assignments assisted the students in correcting and refining their understanding of the course material. Building off a solid theoretical base, students were able to relate how the aircraft should react to the pilot input before relating it back to the equations while creating their own simulation. The strategy empowered students to share their knowledge while deepening their own understanding of the content. Enforcing these strategies early in the semester ensured greater participation and openness from the students in the class. Every student contributed to the classroom learning by taking part in open-ended questions, engaging in discussion, and actively relating their flight simulator experience to the underlying theory.

\section{References}

Bloom, B., Englehart, M. Furst, E., Hill, W., \& Krathwohl, D. (1956). Taxonomy of educational objectives: The classification of educational goals. Handbook I: Cognitive domain. New York, Toronto: Longmans, Green.

Bransford, J. D., and B. Stein. The Ideal Problem Solver. New York: Freeman, 1983.

Brent, R., \& Felder. R. M. (2014). Want your students to think creatively and critically? How about teaching them? Chemical Engineering Education, 48(2), 113-114.

Daly, S. R., Mosyjowski, E. A., \& Siefert, C. M. (2014). Teaching creativity in engineering courses. Journal of Engineering Education, 103 (3), 417-449. http://dx.doi.org/10.1002/jee.20048

Dannenhoffer, J. F., Green, M. A. (2017). Use of a Full-motion Flight Simulator for Teaching Aircraft Performance and Dynamics, 55th AIAA Aerospace Sciences Meeting, 9-13 January 
2017, Grapevine, Texas.

Diaz, A. Freeing the Creative Spirit. San Francisco: Harper Collins, 1992.

Napolitano, M. R., Aircraft Dynamics: From Modeling to Simulation, 2012, John Wiley and Sons Inc.

O'Brien, S., Abulencia, J. P. (2010). Learning through reverse engineering, American Society of Engineering Education.

Provasnik, S., Kastberg, D., Ferraro, D., Lemanski, N., Roey, S., \& Jenkins, F. (2012).

Highlights from TIMSS 2011: Mathematics and science achievement of U.S. fourth- and eighth-grade students in an internation context. Washington, DC: National Center for Education Statistics. http://files.eric.ed.gov/fulltext/ED537756.pdf 